\title{
Storm Surge and Evacuation in Urban Areas during the Peak of a Storm
}

\author{
HIROSHI TAKAGI \\ Tokyo Institute of Technology, Graduate School of Science and Engineering, 2-12-1 Ookayama, \\ Meguro-ku, Tokyo 152-8550, Japan, takagi@ide.titech.ac.jp \\ LI SIYANG \\ Tokyo Institute of Technology, Graduate School of Science and Engineering, 2-12-1 Ookayama, \\ Meguro-ku, Tokyo 152-8550, Japan, Isyiverson0510@gmail.com \\ MARIO DE LEON \\ De La Salle University, Civil Engineering Department, 2401 Taft Avenue, Manila 1004, Philippines, \\ mario.deleon@dlsu.edu.ph \\ MIGUEL ESTEBAN \\ The University of Tokyo, Graduate School of Frontier Sciences, 5-1-5 Kashiwanoha, Kashiwa, \\ Chiba 277-8563, Japan, esteban.fagan@gmail.com \\ TAKAHITO MIKAMI \\ Waseda University, Department of Civil and Environmental Engineering, 3-4-1 Okubo, Shinjuku-ku, \\ Tokyo 169-8555, Japan, takahito8765@gmail.com \\ RYO MATSUMARU \\ Toyo University, Faculty of Regional Development Studies, 5-28-20 Hakusan, Bunkyo-ku, Tokyo \\ 112-8606, Japan, matsumaru@toyo.jp \\ TOMOYA SHIBAYAMA \\ Waseda University, Department of Civil and Environmental Engineering, 3-4-1 Okubo, Shinjuku-ku, \\ Tokyo 169-8555, Japan, shibayama@waseda.jp \\ RYOTA NAKAMURA \\ Waseda University, Department of Civil and Environmental Engineering, 3-4-1 Okubo, Shinjuku-ku, \\ Tokyo 169-8555, Japan, ryota_nakamura617@yahoo.co.jp
}

(C) 2015. This manuscript version is made available under the Elsevier user license http://www.elsevier.com/open-access/userlicense/1.0/ 


\section{Abstract}

2 The present paper examines the impact of floodwater caused by the storm surge brought 3 about by Typhoon Haiyan in 2013, focusing on downtown Tacloban in Leyte Island, the

4 Philippines. A reliable numerical model for predicting such flooding was developed by 5 calibrating the results of field investigations, including footage from a video clip taken 6 during the storm surge. The simulation reveals that flow velocities along the streets in

7 downtown Tacloban reached up to $7 \mathrm{~m} / \mathrm{s}$ due to flow contraction along the high-density 8 blocks of houses, and how water levels reached their peak in just 10 minutes. According

9 to the depth-velocity product criteria, often used for evaluating the vulnerability of 10 people and buildings to floodwaters, only $8 \%$ of the length of streets in downtown

11 Tacloban were within the safe limits that allow pedestrian evacuation. Based on these 12 findings, the present research concludes that pedestrian evacuation in the middle of a 13 storm surge generated by a strong typhoon is a high-risk behaviour. Thus, clearly and 14 objectively, evacuation during this time should not be encouraged, even when seawater 15 intrudes the houses of local residents. In this respect, it would appear imperative that 16 prior to the arrival of the typhoon all residents should evacuate areas at risk of being

17 flooded. Though the flood height was significant in the downtown area, the damage to 18 these houses was limited. If it was not possible for some reason to evacuate prior to the 19 arrival of the typhoon, those in solid houses should first consider vertical evacuation 20 and the possibility that they could survive in their place, rather than courageously 21 evacuating in an unpredictable water flow.

22 Keywords: Typhoon Haiyan (Yolanda), Philippines, Tacloban, Storm Surge, Flooding, 
Pedestrian Evacuation, Inundation, Numerical Simulation, Manning's $n$ value,

24 Depth-velocity product

25

\section{Introduction}

27 Typhoon Haiyan (Yolanda, according to its local name) struck the Philippines on 28 November 8, 2013, causing enormous damage to Leyte, Samar and many other islands.

29 6,245 individuals were reported dead, 28,626 were injured and 1,039 are still missing 30 (NDRRMC, as of 6 March 2014). Such a large death toll was caused not only by the 31 large size of the storm surge, but also due to issues related to the level of knowledge and 32 awareness by local residents on what is a "storm surge" (Esteban et al., 2014; Esteban et 33 al., 2015). Indeed, despite the fact that two historical storm surges had previously 34 devastated Tacloban, one in 1897 killing up to 1,500 and another in 1912 killing 15,000

35 (Langmay et al., 2015), local awareness about such events was non-existent (Esteban et 36 al., 2014). The total economic loss associated with infrastructure and agriculture was 37 estimated to be around 34,366 million pesos (776 million USD), possibly the most expensive natural disaster in the history of the country (TIME, 2013).

Haiyan was one of the strongest typhoons known to have ever made landfall, not only in 41 the Philippines but the entire world (Schiermeier, 2013, Lin et al., 2014). The forward 42 speed of the typhoon, reaching around $41 \mathrm{~km} / \mathrm{hr}$ at landfall, was also unusual amongst other events of comparable intensity during the past 6 decades in the Western North Pacific (Takagi et al., 2015a). Haiyan can be characterized as both the fastest moving 
and strongest typhoon measured in the Philippines. The return period for a Haiyan-class

46 typhoon to make landfall was estimated to be 200 years (Takagi and Esteban, 2015). As

47 a result of its strong intensity, the typhoon caused a massive storm surge in many islands

48 in the Philippines. The storm surge inundated most of the coastline of Leyte Gulf, 49 causing particularly large damage to Tacloban City, the biggest city in Leyte Island. A maximum inundation height of up to 6-7m was observed in this city, where the largest

51 number of casualties took place (Shibayama et al., 2014; Mas et al., 2014; Takagi et al., 52 2015a). It is important to note the local amplification of the water surface elevation due 53 to seiche effects inside Leyte Gulf (Mori et al., 2014).

High inundation heights were observed even outside Leyte Gulf along the east coast of

56 Eastern Samar, which faces the Pacific Ocean and the deep Philippine Trench (Tajima et

57 al., 2014). Maximum hindcast significant wave heights during the storm reached up to $19 \mathrm{~m}$ off Eastern Samar, though they decreased to less than $5 \mathrm{~m}$ in Leyte Gulf near

59 Tacloban (Bricker et al., 2014).

60

61 Understanding the nature and degree of exposure of coastal areas to flooding is 62 important for reducing its effect on people and property. Such assessments may be 63 developed through filed observations, modeling studies, or some combination of the two 64 (Brown et al., 2007). Flood mitigation agencies need to designate floodplains and high 65 hazard zones to identify the risks of flood damage or loss of life. For adequate mapping 66 of flood hazards it is important to examine where dangerous zones are located within a 
67 particular area (Jonkman et al., 2008). For the case of Tacloban city, an early warning

68 system was in place prior to the arrival of Haiyan, which made use of hazard maps and

69 flood drills. These hazard maps were created as part of the READY project, a joint

70 effort in risk mapping among government and donor agencies (Langmay et al., 2015).

71 However, these maps greatly underestimated the extent of the inundation (Langmay et 72 al., 2015).

74 An early evacuation, based on a reliable and accurate warning system, is crucial to 75 survive typhoons and their subsequent storm surges. Local authorities might either 76 advice people to leave or sometimes even conduct forced evacuations, and it appears 77 that a combination of the two was used by the various barangays (smallest 78 administrative divisions in the Philippines) in Leyte and Samar (Esteban et al., 2015).

79 However, despite such evacuation orders and typhoon and storm surge warnings by 80 local authorities and media before the arrival of Typhoon Haiyan, many people did not 81 evacuate. A number of reasons were given by local residents to explain why they stayed 82 in their residences, such as uncertainties in the expected typhoon level, attempting to 83 secure their houses and properties, or problems with poorly maintained evacuation 84 centres (Esteban et al., 2015, Leelawat et al., 2014).

85

86 If residents fail to evacuate prior to the arrival of the typhoon, they may find themselves 87 in a very difficult situation. At that stage it would be hard for them to rationally 88 determine whether they should evacuate or stay home, particularly when extremely 
strong gusts and heavy rain affects the area during the pass of the typhoon. The primary

90 objective of this research is thus to rationally review if it was actually advisable and

91 possible to evacuate during the passage of super typhoon Haiyan. To do so, the authors

92 first conducted a series of field surveys to reveal the extent of inundation in downtown

93 Tacloban. The observed inundations were compared with the water levels computed by

94 a storm surge simulation to validate the model's accuracy. Once the reliability of the

95 numerical model was established, it was possible to examine whether pedestrian

96 evacuation during the passage of strong typhoon would be safe, focusing on Tacloban

97 and typhoon Haiyan as a case study.

\section{Field Survey}

\section{$100 \quad 2.1$ Methodology}

101 The authors conducted field surveys at three different times after the disaster: (1)

102 December 4-13, 2013, (2) May 1-6, 2014, and (3) October 16-21, 2014. The primary 103 purpose of these surveys was to identify the extent of the inundation due to the storm 104 surge along the coastline of Leyte Island. The last two surveys involved a topographical 105 survey of Tacloban, conducted at the same time as the flood investigations (see Fig.1). 106 The storm surge inundation height was established by checking physical evidence and 107 interviewing local residents at each site. Laser range finders and GPS receivers were 108 used to establish the inundation height at each location (with reference to the local sea 109 level) to within a few centimetres accuracy, which was adjusted to take into account the 110 tidal levels at the time of the survey and during the passage of the typhoon. Laser range 
111 finders were also used for surveying the ground elevation of different parts of

112 Tacloban's downtown, essentially densely populated residential areas built on top of

113 both flat and hilly terrains.

114

115 Another important factor investigated in the present study was the flow velocity at a 116 particular location in the downtown area of Tacloban. Interestingly, a video clip taken

117 from a hotel in this area (Hotel Alejandro) during the peak of the storm surge shows that 118 the flow was relatively slow, and nearby local residents could walk across the flooded 119 street to evacuate from their house to the hotel shown in Fig.2(a) (iCyclone, 2013). The 120 flow velocity and direction was roughly estimated by visual investigation through the 121 elapsed time shown imbedded in the video clip. The distance moved by pieces of 122 floating rubbish captured in the video was estimated by reference to a photo showing a 123 measuring staff, taken by the authors during their surveys (Fig.2(c)). Finally, the 124 velocity could be calculated by dividing the time it took for the debris to cross the 125 points shown in the measuring staff. Obviously, a certain degree of estimation error is 126 present in the visual measurement with a floating object. However, such errors can be 127 minimized by considering and calculating the speed of the multiple objects that 128 simultaneously flow within the video. 


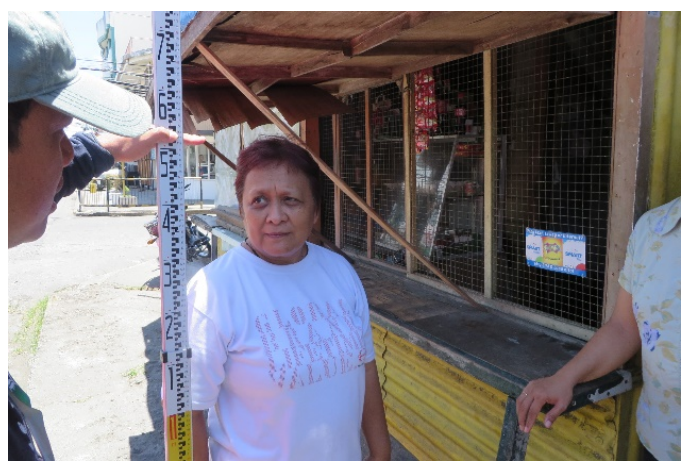

(a) Inundation height

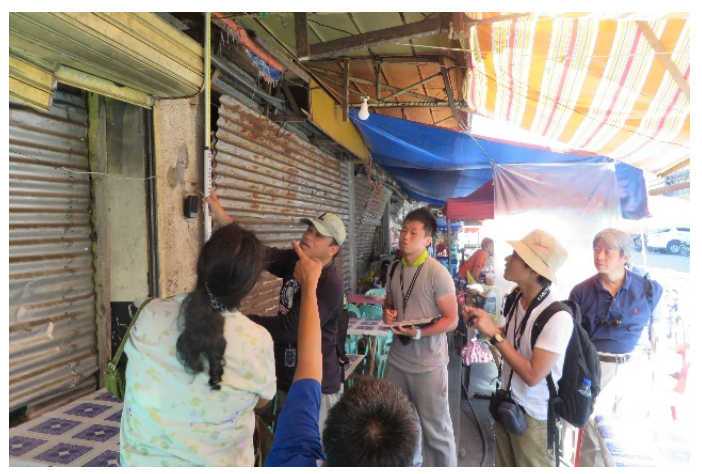

(c) Inundation height

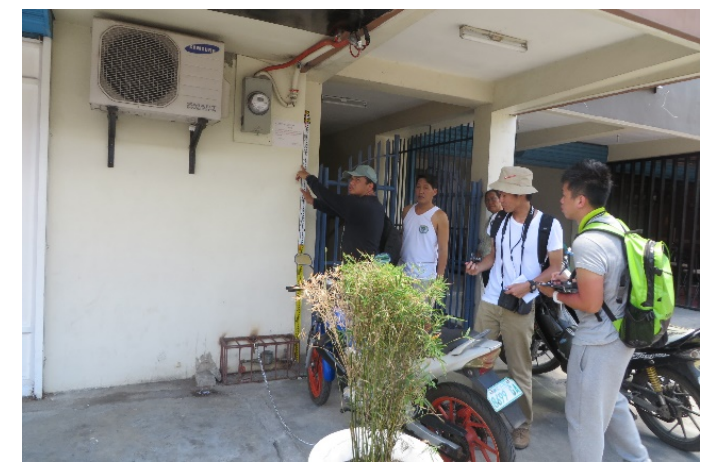

(b) Inundation height

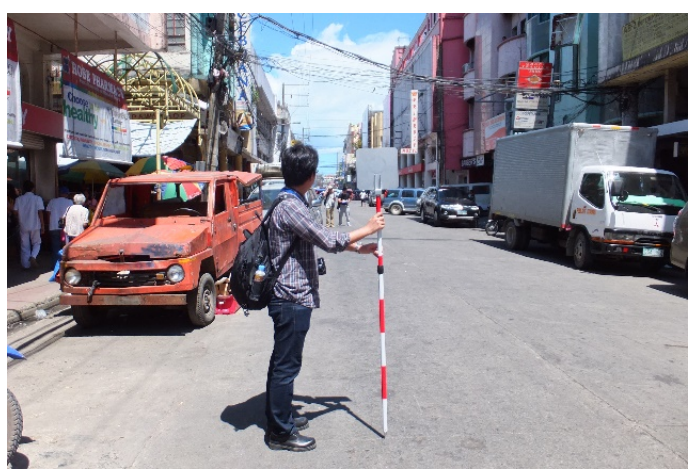

(d) Topographical survey

Fig.1 Site investigation on May 2014 at Tacloban in Leyte Island, the Philippines 

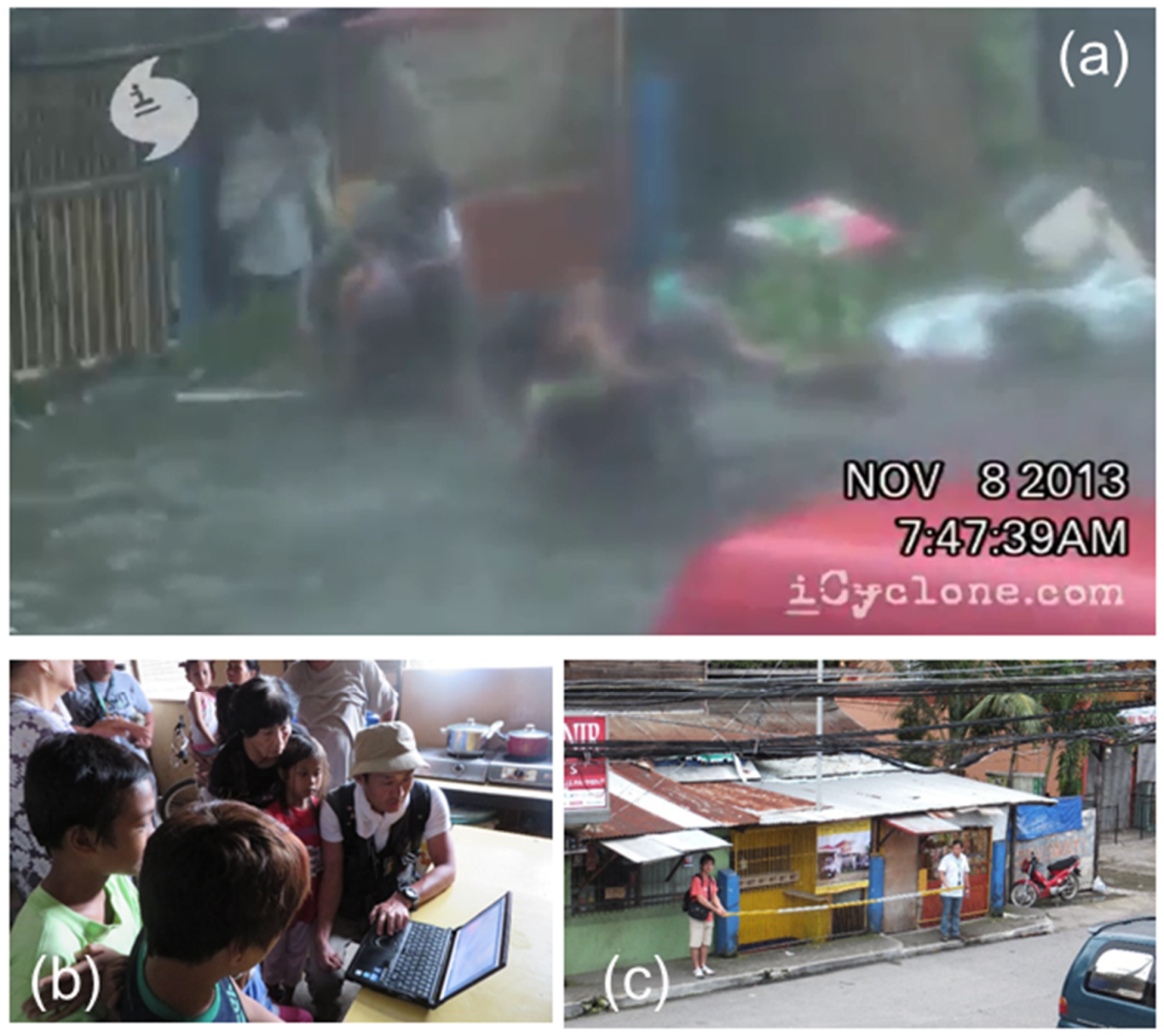

133 Fig.2 Field investigations nearby Alejandro Hotel: (a) iCyclone’s video clip taken from

134 the hotel during the surge peak, showing family members exiting their house and

135 evacuating to the hotel, (b) interview with the family featured in iCyclone's video to

136 understand more details about the situation during the storm surge, and (c) a photo

137 with a measuring staff taken from the same position where the video clip was filmed,

138 and which was used for measuring the flow velocity during the flood

\subsection{Results}

141 Fig.3 shows the topography around downtown Tacloban, which was reproduced by the 
142 authors using the measured elevations, together with a satellite image showing the city 143 before the typhoon. In this area many houses were built on relatively low-lying land, 144 only $1-3$ metres above sea level. The storm surge heights, which were measured from 145 the astronomical tide at the time of typhoon landfall, are plotted in Fig.4, showing that 146 inundation took place even in the middle part of the downtown area. Though the flood 147 height was significant (in the rage of 0.6 to $4.2 \mathrm{~m}$ ), the damage to these houses was not 148 as severe as in other areas of the city that had informal settlements, as shown in Fig.1 149 and Fig.2. Essentially, houses in the downtown area where typically rather strong 150 cement or concrete two-story or higher buildings, and thus floodwaters intruded through 151 the streets (rather than passing over the roofs of houses).

152

153 The flow velocity at the street in front of Alejandro Hotel was estimated to be about $1540.6 \mathrm{~m} / \mathrm{s}$. This agrees well with field survey observations, as water flow at such low speed 155 will not cause catastrophic damage to houses, though minor damage could be observed 156 in all areas that were flooded. It also explains why it was possible for local residents to 157 walk through the water flow shown in Fig.2(a). 

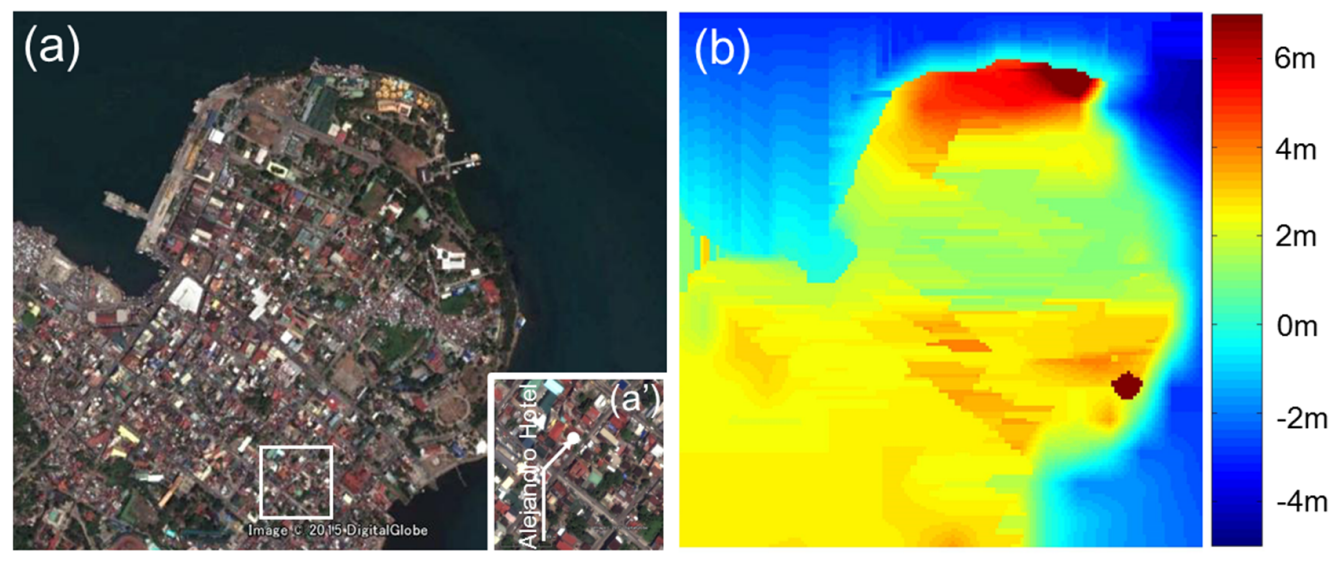

160 Fig. 3 (a) Satellite image of Tacloban taken before the typhoon (@Google Earth), (a’)

161 densely populated residential area around Hotel Alejandro, and (b) Topography of

162 Tacloban which was used in the simulation

163

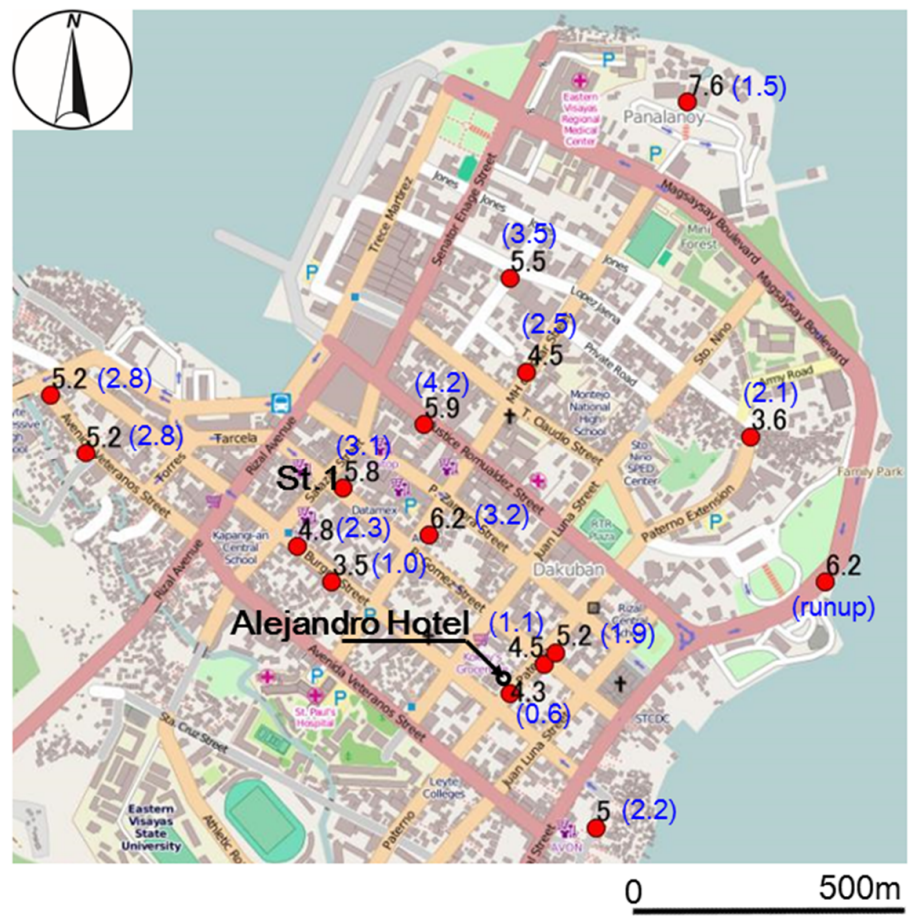

Fig.4 Storm surge heights (black) adjusted to the tidal level at the time of passage of the

166 typhoon, and inundation depths above ground level (blue) measured around Tacloban 


\section{Storm Surge Simulation}

\subsection{Methodology}

171 The authors performed numerical simulations to estimate the spatial distributions of the 172 storm surges using three different scales. First, the simulation was carried out for a wide 173 area which encompasses most of the Philippines, in order to assess which areas of the 174 country were affected. Then, a more detailed simulation was carried out for San Pedro

175 Bay in Leyte Gulf, an area where the storm surge engulfed and claimed thousands of 176 lives. The reliability of the numerical simulation for these two domains was already 177 confirmed by Takagi et al. (2015a), showing a storm surge larger than 3 metres along 178 the entire bay, and up to 6 metres high in its inner part. Such simulation results agree well with the observations of field surveys (Takagi et al., 2015a, Lagmay et al., 2015).

In the present research the authors carried out detailed inundation simulations that focused on Tacloban's downtown (1.7km x $1.7 \mathrm{~km}$ square grids). The simulation used a

183 10m fine computational grid and incorporates details of the city down to the block level to examine how the urban geometry can mitigate or intensify the impact of flooding.

In previous studies, many types of numerical codes have been applied to reproduce coastal floods due to recent major storm surges or tsunamis (e.g. the COMCOT model

188 for the 2004 Indian Ocean tsunami (Wijetunge et al., 2008), the ADCIRC model for 
189 Hurricanes Katrina and Rita (Dietrich et al., 2011), or the FVCOM model for the 2008 190 Cyclone Nargis (Tasnim et al., 2015) and for the 2011 Tohoku Earthquake Tsunami 191 (Sasaki et al., 2012)).

192

193 In this study, the authors applied the parametric typhoon model developed by Takagi et 194 al. (2012, 2014, 2015c), coupled with the fluid dynamics model Delft3D-FLOW to 195 estimate the extent of the storm surge. The typhoon model calculates both the pressure 196 and wind fields using parameters obtained from the typhoon track dataset, namely, the 197 central positions and pressures at every recording period. Delft3D-FLOW was then used 198 to simulate how a storm surge travels from the deep sea to shallow water, and eventually 199 flows over downtown Tacloban. Though this model can be applied to a 3D domain, the 200 present study used a 2D horizontal grid, and thus the code is equivalent to a non-linear 201 long wave model, commonly used for storm surge simulation.

203 The standard drying and flooding algorithm in Delft3D-FLOW is efficient and accurate 204 for coastal regions, tidal inlets, estuaries, and rivers. In combination with the flooding 205 scheme for advection in the momentum equation, the algorithm known as "drying and 206 flooding” in this numerical model is effective and accurate for rapidly varying flows 207 with large water level gradients due to the presence of hydraulic jumps or the 208 occurrence of bores as a result of dam breaks (Stelling et al., 1986, Stelling and 209 Duinmeijer, 2003). 
211 The numerical settings used in the model are summarized in Table.1. Data regarding the

212 typhoon and bathymetry in the target area were obtained from the Japan Meteorological

213 Agency and The General Bathymetric Chart of the Oceans (GEBCO) datasets,

214 respectively. The simulation was run for 18 hours, which encompasses the final

215 approach of the typhoon towards Tacloban, and also its passage through the rest of 216 Leyte, Cebu and Panay islands. The bathymetry for the detailed simulation was

217 produced by digitizing a nautical chart of NAMRIA (National Mapping and Resource 218 Information Authority). The astronomical tide at Tacloban at the time of landfall was 219 calculated by using the software WXTide32, showing that the tidal level was very 220 similar to MLLW (Mean Lower Low Water, which corresponds to the chart datum), 221 with the difference to this level being only a few centimetres. Therefore, the bathymetry 222 of the chart was used directly in the simulation (i.e. without it having to be modified for 223 tide levels).

225 Manning's $n$ coefficient is one of the most important parameters for the accurate 226 simulation of inundation over land. For the case of tsunami inundation simulations 227 MLIT (2012) recommends using a Manning's $n$ value in the range of 0.04 to 0.08 for 228 the case of residential areas. Arcement and Schneider (1984) propose that the estimation 229 of $n$ values for a flood plain should depend on soil surface, surface irregularities, size of 230 the cross section, obstructions, vegetation and sinuosity of the flood plain. Taking the 231 maximum numbers from the range of possible values of each of these factors, the 232 maximum $n$ value calculated by their method is 0.25 . It is thus clear that Manning's $n$ 
233 value can take a wide variety of values depending on the conditions considered.

234 Furthermore, it appears that the $n$ value for coastal floods in an urban area has not been

235 researched in detail because such extreme flood events rarely occur. In light of the

236 constraints regarding the information available, the authors chose to conduct a series of

237 simulations with different settings of Manning's $n$, in order to find an appropriate value

238 that best describes the flow velocity in front of Alejandro Hotel.

Table 1. Numerical model and settings

\begin{tabular}{|l|l|}
\hline Typhoon Path & $\begin{array}{l}\text { JMA Typhoon Best Track } \\
\text { http://www.jma.go.jp/jma/jma-eng/jma-center/rsmc-hp-pub- } \\
\text { eg/trackarchives.html }\end{array}$ \\
\hline Typhoon Model & $\begin{array}{l}\text { Pressure: empirical estimation by Myers Formula, } \\
\text { Wind: Gradient winds considering Super-gradient } \\
\text { Wind effect }\end{array}$ \\
\hline Fluid Dynamics Model & Delft3D Flow Ver. 3.42 \\
\hline Domain & $\begin{array}{l}\text { Cartesian (UTM51N), grid @3000m (Philippines), } \\
\text { @100m (San Pedro Bay), and @10m (Tacloban) }\end{array}$ \\
\hline Bathymetry & $\begin{array}{l}\text { GEBCO_08 Grid (Philippines) } \\
\text { NAMRIA Chart (San Pedro Bay and Tacloban) }\end{array}$ \\
\hline Terrain Data & $\begin{array}{l}\text { ASTER GDEM 30m Resolution (San Pedro Bay ) } \\
\text { Measured by the authors (Tacloban) }\end{array}$ \\
\hline
\end{tabular}




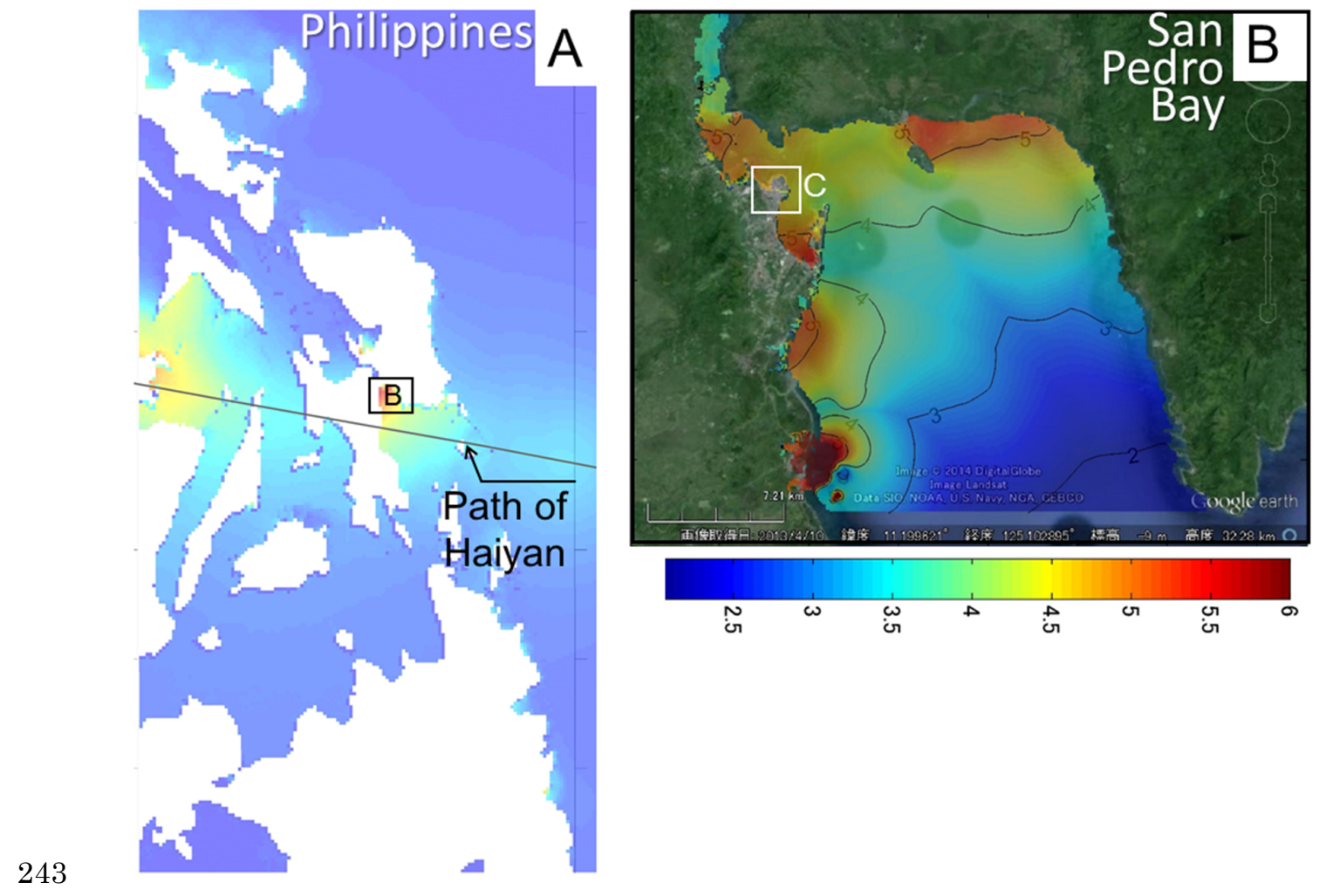

244 Fig.5 Three-scale computational domains: (A) Country scale, (B) Bay scale (both after

245 Takagi et al., 2015a), and (C) City scale, focusing on Tacloban (present research). Color

246 contours present the maximum storm surge heights during the passage of the typhoon

\section{$248 \quad 3.2$ Results}

249 Inundation simulations were conducted for a variety of values of Manning's $n$ 250 coefficient in the range between 0.02 and 0.32 . An $n=0.04$ was found to provide the 251 results that best fit the flow velocities in front of Alejandro Hotel (Fig.6). This value 252 falls within the 0.04 to 0.08 range recommended by MLIT (2012). However, Takagi and 253 Bricker (2014) and Bricker et al. (2015) point out that the recommended values by 254 MLIT would underestimate the mitigating effect of buildings when not taking into 
account urban geometries (such as streets and residential blocks). The present study

256 confirms that the simulation, based on the recommended values by MLIT (2012), could

257 yield a good estimation when urban geometries are appropriately incorporated into the 258 model.

259

260 Figure 7 presents a time series of the simulated flow velocity with $n=0.04$, comparing it

261 to the estimated velocity calculated through the observation of the iCyclone video.

262 Though the simulated peak velocities agree well with the observed velocity, there is a 263 slight difference in the arrival time of the floodwater. According to the video the 264 strongest flow occurred before 8:00AM, as indicated in Fig.2, whereas the flood in the 265 simulation starts after 8:00AM. This 30-minute difference could have been caused by a 266 discrepancy between the typhoon’s location recorded by the JMA Typhoon Best Track 267 Data and the actual typhoon course. Basically, the JMA Typhoon Best Track Data is 268 given at 3 hour intervals and therefore the position of the simulated typhoon between 269 these data points might be slightly inaccurate. Nevertheless, the flow would otherwise 270 appear to be well simulated, and for example, during the period of peak flow water 271 moves along the street in the southwest direction, which corresponds exactly with the 272 actual direction shown in the video.

274 Figure 8 shows how the simulated and observed storm surge heights at the various 275 locations shown in Fig. 4 are in good agreement at many points, such as Alejandro 276 Hotel. In fact, the coefficient of determination $R^{2}$, which is a number that indicates how 
well data fits a statistical model, was calculated as 0.574 . This implies that the 278 calibration of Manning's $n$ value, by using the observed flow velocity at even just one 279 point, can be expected to improve the accuracy of the simulation of storm surge heights.

281 However, the authors do acknowledge that there are still many uncertainties that present 282 in the numerical results. The best estimated Manning's $n$ could also vary according to 283 the local topography, which can create various levels of resistance to the flow due to 284 differences in bottom friction, friction on the walls and parked cars. Despite this, the $n$ 285 value in the present study was set to be uniform throughout the entire land domain. 286 Mignot et al. (2006) attempted to improve the reliability of an urban flood modeling 287 with two different $n$ values of 0.025 and 0.050 , according to different road widths. 288 Changes in Manning's $n$ in this manner could be one possible option to further improve 289 the estimation of velocities and inundation depths. It should also be noted that the flow condition at some particular locations in the downtown area can be considered to be 291 supercritical. The energy loss during such a regime cannot be correctly evaluated 292 because the formulation in terms of friction used in the present model merely assumes subcritical flow (though Manning's $n$ can be still applied to a rapid flow, such as that induced by a tsunami’s overflow, by using an appropriate value, see Bricker et al., 2015). Therefore, it is important to recognize that the numerical settings used in this study do not necessarily provide the best options for other cases or areas. 


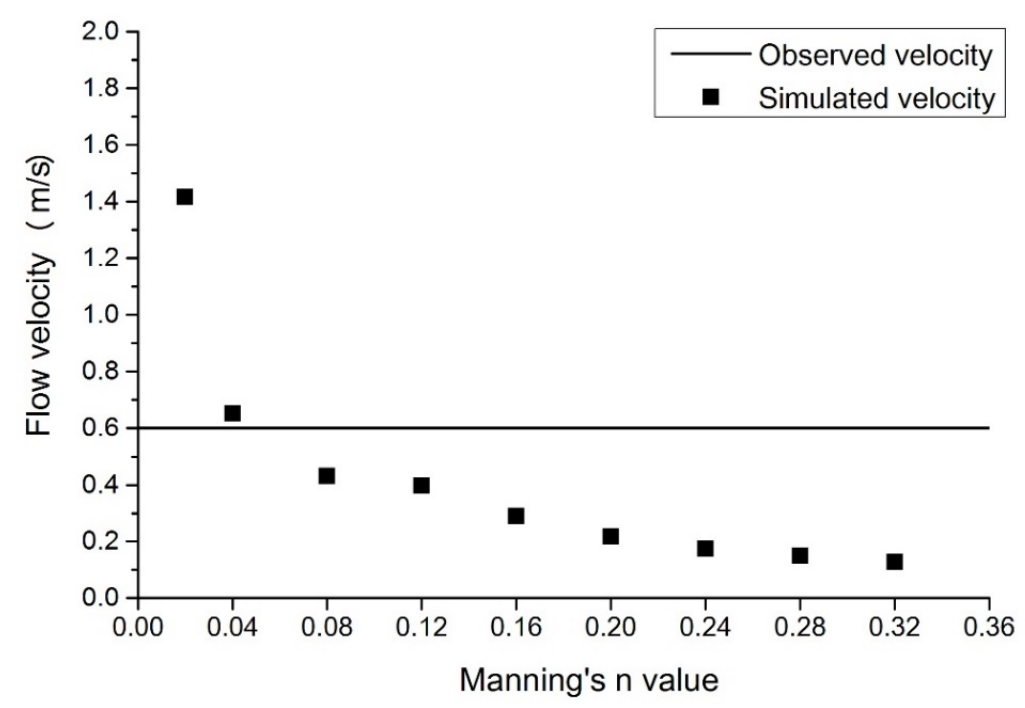

299

Fig.6 Flow velocity varies with Manning's $n$ value

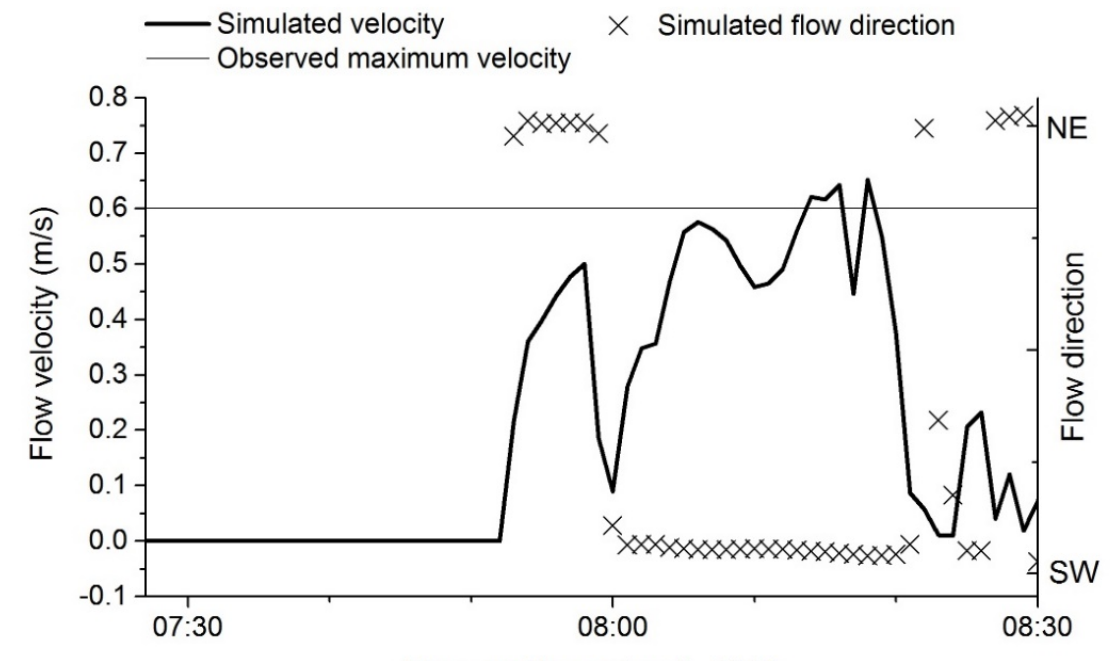

301

Time on November 8, 2013

$302 \quad$ Fig.7 Comparison between simulated and observed velocities, together with simulated flow direction (direction can be identified by the azimuth in Fig.4) 


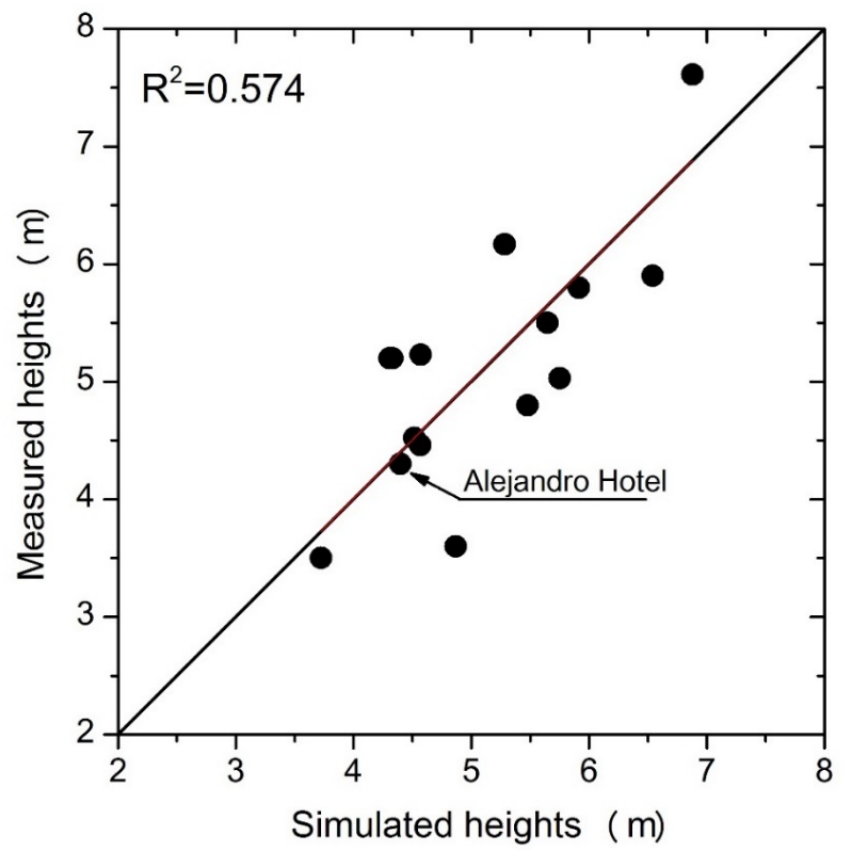

Fig.8 Comparison of storm surge between measured and simulated heights at 15 locations in Tacloban downtown

\section{Discussion}

This section will discuss the characteristics of the floodwater in general and the flow

311 velocity along the streets in particular, which has a great influence on the chance that 312 evacuees caught in the flood can survive. According to an experimental study using a 313 large sized water flume (Suga et al., 1995), a 60 year old male did not experience any 314 fear when he walked against a water flow as high as his crotch with speeds up to $0.8 \mathrm{~m} / \mathrm{s}$.

315 In contrast, he felt intense fear and could not walk without supporting ropes when the 316 flow reached a height of $1 \mathrm{~m}$ or a velocity of $1 \mathrm{~m} / \mathrm{s}$. Nishihata et al. (2005) estimated that 317 the maximum inundation depth at which people can safely evacuate is around $0.7 \mathrm{~m}$. 
318 Likewise, in areas with high flow velocity people may not be able to evacuate because 319 of friction instability (sliding), no matter how shallow the inundation depth. Therefore, 320 the authors feel safe to presume that the family featured in iCyclone's video could cross 321 the flooded street because the flow in front of Alejandro Hotel was relatively slow, with 322 a velocity $0.6 \mathrm{~m} / \mathrm{s}$ or lower, as Fig.7 indicates. Figure 9 shows the maximum flow 323 velocities calculated during the passage of the typhoon. According to this it appears that 324 the flow velocity at the hotel was relatively calm compared to other parts of the city, 325 which enabled them to evacuate. In contrast, flow appears to have been particularly 326 intense along certain streets, possibly due to flow contraction, with flow velocities of up 327 to $7 \mathrm{~m} / \mathrm{s}$ in places.

It is worth noting that friction instability appears to occur earlier than moment 330 instability (toppling) for the combination of shallow depth and high velocities (Jonkman et al., 2008). Also, individuals who are males, middle-aged, heavy, tall, in good physical 332 condition, and lightly clad are able to, on average, remain standing in higher 333 depth-velocity products (Abt et al., 1989). Some authors have proposed a critical 334 depth-velocity product to indicate a person's instability in flood waters, which would be 335 a combination of the depth and the velocity of the flood (Jonkman et al., 2008). Wright 336 et al. (2010) summarises that the depth-velocity product of $1.0 \mathrm{~m}^{2} / \mathrm{s}$ as the safe limit for 337 pedestrians. Figure 10 presents the histogram of the maximum depth-velocity product 338 derived by summing up the values at all the computational grids along the streets 339 surrounded by building blocks, i.e. excluding the roads that directly face the sea. This 
340 figure shows that only $8 \%$ of the total street areas in the downtown section of Tacloban

341 could have been classified as being within the safe limit for pedestrian evacuation 342 during the peak of the storm surge.

344 The depth-flow velocity product is also considered as a critical parameter leading to the 345 damage or the collapse of buildings. Pistrika et al. (2010) proposes residential building 346 damage categories that can be determined by the depth-velocity product $(d v)$, as 347 follows:

According to this criteria residential houses can withstand much stronger floodwaters than people. Although the simulated depth-velocity product in Fig.10 reached up to $35510 \mathrm{~m}^{2} / \mathrm{s}$, it can be noted that water does not flow normal to the houses but typically along 356 the roads, which would further alleviate the impact of the flood. In fact, in the course of 357 the surveys conducted by the authors there was little evidence that any residential houses nearby the locations surveyed in Fig.4 suffered any significant physical damage, 359 as shown also by Fig.1 and Fig.2.

361 The rise time of the storm surge was estimated to be less than half an hour (Takagi et al., 
362 2015b), which correlates well with interviews with survivors (Esteban et al., 2015).

363 Fig.11 also shows how water depth and velocity would have risen quickly at the street 364 indicated by St. 1 in Figure 9, with the depth-velocity product exceeding the safety limit 365 of $1.0 \mathrm{~m}^{2} / \mathrm{s}$ in just 10 minutes. Therefore, the case of the family featured in the iCyclone 366 video, who successfully evacuated across their street to Hotel Alejandro, can be 367 perceived as a case of good luck, brought about by the fact that the flood around the 368 area was much less violent than in other areas in downtown Tacloban.

370 Although this would appear rather intuitive, in fact comparatively little research has 371 focused on ascertaining such dangers and explaining why anecdotal evidence of 372 evacuation by pedestrians during the Haiyan's storm surge was possible. The present 373 research establishes that success in such cases was often a matter of luck and timing, as 374 in most cases flood inundation depths and velocities would have been too high to allow 375 any evacuation. In this sense, the results also explain why witnesses often reported how 376 it was impossible to swim in the flood waters due to the high turbulence, and how many 377 caught in them died (Esteban et al., 2015). 


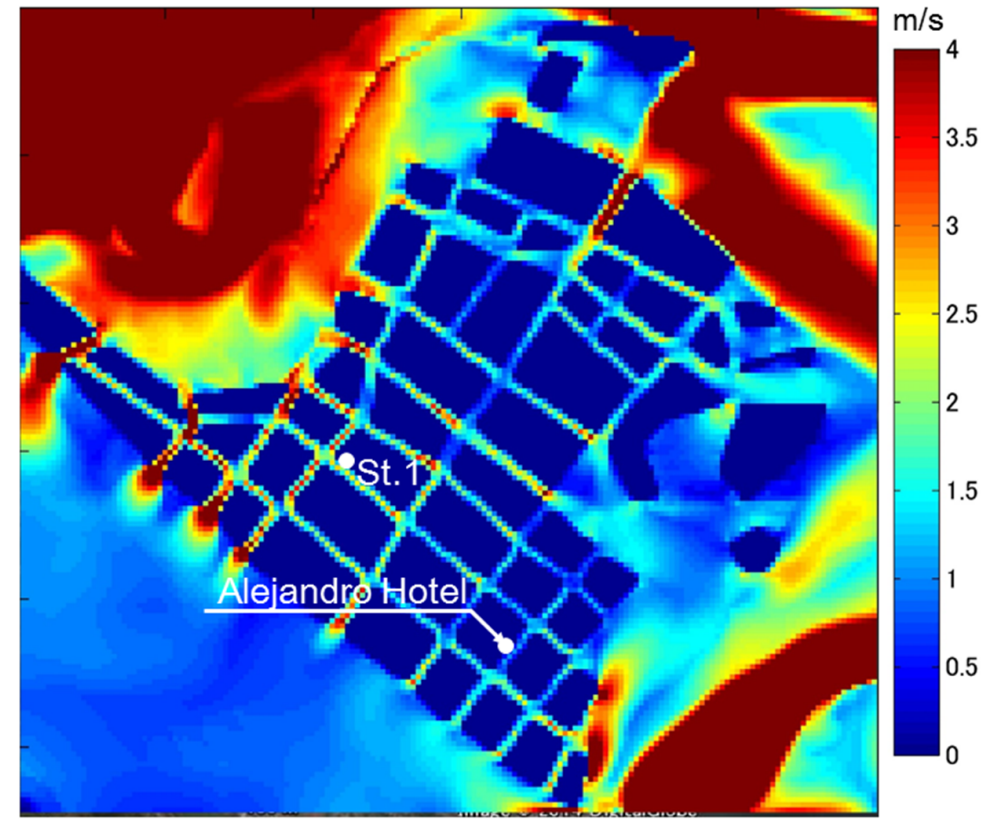

Fig.9 Maximum flow velocity simulated along the streets of Tacloban downtown

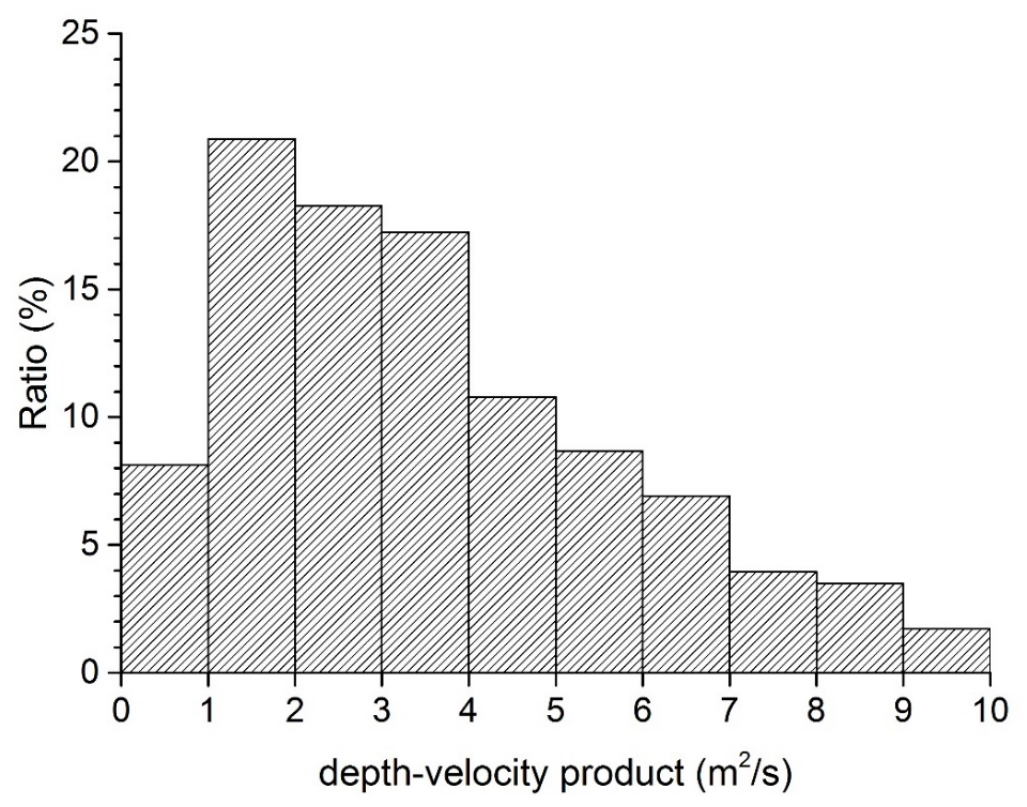

Fig.10 Histogram of the maximum depth-velocity product in Tacloban downtown 


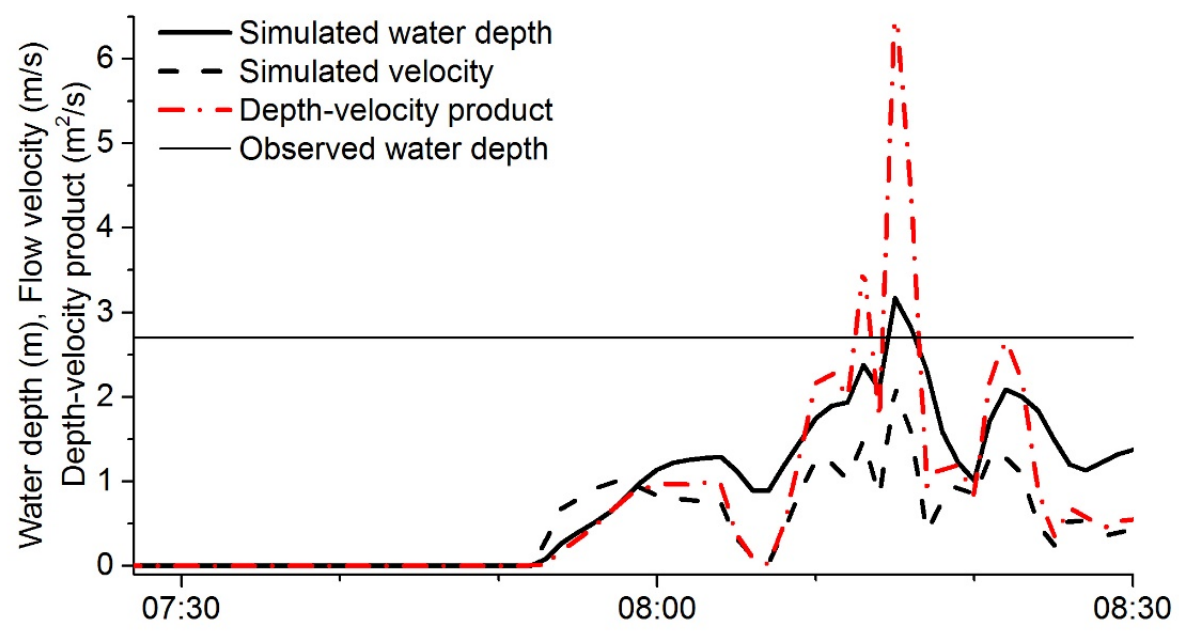

Time on November 8, 2013

385 Fig.11 Variations in water depth and velocity at St.1 (the location shown in Fig.4 and

\section{Conclusion}

389 In the present work the authors reported on field investigations carried out in downtown

390 Tacloban to reveal the impact of floodwater caused by the storm surge due to Typhoon

391 Haiyan in 2013. Inundation levels were confirmed by visual inspection and interviews

392 with local residents. The results of a numerical model, calibrated by the flow patterns

393 captured in a video clip by iCyclone, agree well with the observed inundation heights.

395 Local residents of coastal areas have to consider evacuating from their houses when 396 facing a strong typhoon that can cause extensive flooding. Particularly, it is inevitable that they will be wanting to evacuate once floodwaters directly enter their houses, 398 though at such point it is often hard for them to rationally determine whether they 399 should evacuate or stay in order to survive. By using the model it was then possible to 
understand the hazard posed by storm surge flooding, and the risks involved in

401 pedestrian evacuation during the passage of a strong typhoon. Based on such analysis it 402 can be concluded that pedestrian evacuation during a storm surge can be considered as 403 high-risk behaviour, at least for the case of downtown Tacloban during the peak of 404 storm.

405

406 Also, it was clear that many residential houses in downtown Tacloban withstood the 407 flood without suffering any significant physical damage, despite high flow velocity 408 along the streets, which reached up to $7 \mathrm{~m} / \mathrm{s}$ in places. From these findings, it would 409 appear that pedestrian evacuation during the peak of typhoons could be more hazardous than staying in houses, provided that the house was of sufficient height to allow vertical 411 evacuation to its upper floors.

However, the present research only deals with the case of Tacloban City and Typhoon 414 Haiyan in 2013, and is clearly not sufficient to generalize such conclusions to all cases. 415 Therefore, more detailed investigations for other stretches of the coastline and typhoons 416 would be needed before a definitive conclusion can be reached. As a preliminary conclusion, and although this would appear somehow obvious in the context of storm surge risk management, evacuation should be encouraged prior to the arrival of a 419 typhoon, particularly for those living in low-level and low-strength housing. Even if it 420 was not possible for some reason to evacuate prior to the arrival of the typhoon, 421 evacuation should not be encouraged when people find that seawater intrudes into their 
422

423

424

425

426

427

428

429

430

431

432

433

434

435

436

437

438

439

440

441

442

443

properties. Though the flood height was significant in the downtown area, the damage to these houses was limited. Particularly, those in such solid houses should first consider vertical evacuation and the possibility that they could survive in their place, rather than courageously evacuating in an unpredictable water flow.

\section{Acknowledgements}

The funds for the present research were provided by JSPS KAKENHI Grant Number 26702009 (Tokyo Institute of Technology), J-RAPID Program of Japan Science and Technology Agency (JST) (grant to Tokyo Institute of Technology), and Strategic Research Foundation Grant-aided Project for Private Universities from Ministry of Education, Culture, Sports, Science and Technology (MEXT) (Waseda University).

\section{References}

Abt, S.R., Wittier, R.J., Taylor, A., Love, D.J. (1989) Human stability in a high flood hazard zone, Journal of the American Water Resources Association, 25: 881-890. doi: 10.1111/j.1752-1688.1989.tb05404.x

Arcement, G.J., Jr., and Schneider, VR. (1984) Guide for Selecting Manning's Roughness Coefficients for Natural Channels and Flood Plains. Report No. FHWA-TS-84-204, Federal Highway Administration.

Bricker J D, Takagi H, Mas E, Kure S, Adriano B, Yi C, Roeber V (2014) Spatial Variation of Damage due to Storm Surge and Waves during Typhoon Haiyan in the Philippines, Journal of Japan Society of Civil Engineers, Ser. B2 (Coastal 
Bricker J D, Gibson S., Takagi H., Imamura F. (2015) On the Need for Larger Manning's Roughness Coefficients in Depth-Integrated Tsunami Inundation Models, Coastal Engineering Journal, Vol. 57, Issue 02, 13 pages, DOI: $10.1142 / S 0578563415500059$

Brown, J. D., Spencer T., Moeller I. (2007) Modeling storm surge flooding of an urban area with particular reference to modeling uncertainties: A case study of Canvey Island, United Kingdom, Water Resour. Res., 43, W06402, doi:10.1029/2005WR004597.

Dietrich, J. C., M. Zijlema, J. J. Westerink, L. H. Holthuijsen, C. Dawson, R. A. Luettich, R. E. Jensen, J. M. Smith, G. S. Stelling, and G. W. Stone. (2011) Modeling hurricane waves and storm surge using integrally-coupled, scalable computations." Coastal Engineering 58, No. 1, pp. 45-65.

Esteban M., Matsumaru R., Takagi H., Mikami T., Shibayama T., Leon M., Valenzuela V. P., Thao N.D. (2014), Study on disaster information dissemination and people's response for evacuation -the case of the 2013 Typhoon Yolanda (Haiyan)-, Journal of Japan Society of Civil Engineers, Ser. B3 (Ocean Engineering), Vol. 70, No. 2 p. pp.1218-1223, http://dx.doi.org/10.2208/jscejoe.70.I_1218

Esteban, M., Valenzuela, V. P., Yun, N. Y., Mikami, T., Shibayama, T., Matsumaru, R., Takagi, H., Thao, N. D., De Leon, M., Oyama, T., Nakamura, R. (2015) Typhoon Haiyan 2013 Evacuation Preparations and Awareness. J-SustaiN Journal, Vol.3, No.1, 9 p. 
466

467

468

469

470

471

472

473

474

475

476

477

478

479

480

481

482

483

484

485

486

487

iCyclone (2013) Super Typhoon HAIYAN (YOLANDA): Eyewall Video, http://www.icyclone.com/ (Accessed on December 20, 2013)Irish, J. L. and Resio, D. T. (2010) A hydrodynamics-based surge scale for hurricanes. Ocean Eng. 37, 69-81

Jonkman S.N., Penning-Rowsell E. (2008) Human instability in flood flows, Journal of the American Water Resources Association, 44(4), pp.1-11.

Lagmay, A. M. F., Agaton, R. P., Bahala, M. A. C., Briones, J. B. L. T., Cabacaba, K. M. C., Caro, C. V. C., Dasallas, L. L., Gonzalo, L. A. L., Ladiero, C. N., Lapidez, J. P., Mungcal, M. T. F. Puno, J. V. R., Ramos, M. M. A. C., Santiago, J., Suarez, J. K. and Tablazon, J. (2015) Devastating storm surges of Typhoon Haiyan. Intl. Journla of Disaster Risk Reduction, 11, pp. 1-12

Leelawat N., Mateo C. M. R., Gaspay S. M., Suppasri A., Imamura F. (2014) Filipinos’ views on the disaster information for the 2013 Super Typhoon Haiyan in the Philippines, International Journal Sustainable Future for Human Security, J-SustaiN, Vol.2, No.2, pp.16-28.

Lin I. I., Pun I. F., Lien C. C. (2014) “Category-6” supertyphoon Haiyan in global warming hiatus: Contribution from subsurface ocean warming, Geophys. Res. Lett., doi 10.1002/2014GL061281

Mas E., Bricker J., Kure S., Adriano B., Yi C. Suppasri, A., Koshimura S. (2014) Field survey report and satellite image interpretation of the 2013 Super Typhoon Haiyan in the Philippines, Nat. Hazards Earth Syst. Sci, Discuss., 2, pp.3741-3767.

Mignot E., Paquier A., Haider S. (2006) Modeling floods in a dense urban area using 
2D shallow water equations, J. of Hydrology, No.327, pp.186-199.

MLIT (2012) Guide to determining the potential tsunami inundation (Version 2.00). Seacoast Office, Water and Disaster Management Bureau, Ministry of Land,

Mori, N., Kato M, Kim S., Mase H., Shibutani Y., Takemi T., Tsuboki K., Infrastructure, Ministry of Land, Infrastructure, Transport and Tourism Yasuda T. (2014) Local amplification of storm surge by Super Typhoon Haiyan in

$$
\text { Leyte Gulf, Geophys. Res. Lett., 41, 5106-5113, doi:10.1002/2014GL060689. }
$$

Nishihata T., Moriya Y., Tamura T., Takimoto K, Miura H. (2005) Experimental study on the condition of evaluation under flood situation caused by tsunami. Annual Jour. Coastal Eng., JSCE 52, pp. 1256-1260.

NDRRMC (2014) Effects of Typhoon "YOLANDA" (HAIYAN), SitRep No.106, 6 March 2014

Pistrika A. K., Jonkman S. N. (2010) Damage to residential buildings due to flooding of New Orleans after Hurricane Katrina, Nat Hazards, 54:413-434, DOI 10.1007/s11069-009-9476-y

Sasaki J., Ito K., Suzuki T., Wiyono R. U. A., Oda Y., Takayama Y., Yokota K., Furuta A., Takagi H. (2012) Behavior of the 2011 Tohoku Earthquake Tsunami and Resultant Damage in Tokyo Bay, Coastal Engineering Journal, Vol. 54, No. 1, 26 p., DOI: 10.1142/S057856341250012XSuga K., Uesaka T., Yoshida T., Hamaguchi K., Chen Z. 508 hydraulic engineering, JSCE, Vol.39, pp.879-882.

509 Schiermeier, Q. (2013) Did climate change cause Typhoon Haiyan. Nature 
511 Shibayama T., Matsumaru R., Takagi H., Leon M., Esteban M., Mikami T., Oyama T., $512 \quad$ Nakamura R. (2014) Field survey and analysis of storm surge caused by the 2013 513 Typhoon Yolanda (Haiyan), Journal of Japan Society of Civil Engineers, Ser. B3 514 (Ocean Engineering), Vol. $70 \quad$ (2014) No. 2, pp.1212-1217, $515 \quad$ http://dx.doi.org/10.2208/jscejoe.70.I_1212

516 Stelling G. S., Wjersma A. K., Willemse J. B. T. M. (1986) Practical aspects of accurate 517 tidal computations, Journal of Hydraulic Engineering, 112 (9), pp.802-817.

518 Stelling G. S., Duinmeijer S.P.A. (2003) A staggered conservative scheme for every 519 Froude number in rapidly varied shallow water flows, International Journal $520 \quad$ Numerical Methods in Fluids, Vol.43, pp.1329-1354.

521 Takagi, H., Kashihara, H., Esteban, M. and Shibayama, T. (2011) Assessment of Future 522 Stability of Breakwaters under Climate Change, Coastal Eng. J., Vol. 53, No. 1, pp. 21-39, DOI: 10.1142/S0578563411002264

524 Takagi H, Thao N D, Esteban M, Tam T T, Knaepen H L, Mikami T. (2012) Assessment 525 of the Coastal Disaster Risks in Southern Vietnam, Journal of Japan Society of Civil 526 Engineers, Ser. B3 (Ocean Engineering), Vol. 68, No. 2, pp. 888-893, 527 http://dx.doi.org/10.2208/jscejoe.68.I_888

528 Takagi H., Bricker J D. (2014) Assessment of the effectiveness of general breakwaters 529 in reducing tsunami inundation in Ishinomaki, Coastal Eng. J., Vol. 56, No. 04, $530 \quad$ DOI: $10.1142 / S 0578563414500181$

531 Takagi H., Thao N.D., Esteban M. (2014) Tropical Cyclones and Storm Surges in 

Climate Change in Vietnam, pp.3-16, DOI: 10.1016/B978-0-12-800007-6.00001-0

534

535

536

537

Takagi H., Esteban M., Shibayama T., Mikami T., Matsumaru R., Nguyen D. T., Oyama T., Nakamura R. (2015a) Track Analysis, Simulation and Field Survey of the 2013 Typhoon Haiyan Storm Surge, Journal of Flood Risk Management, DOI: 10.1111/jfr3.12136

Takagi H., Mario L.D., Esteban M., Mikami T., Nakamura R. (2015b) Storm Surge due to 2013 Typhoon Yolanda in Leyte Gulf, the Philippines, IN: Esteban M., Takagi H., Shibayama T. Handbook of Coastal Disaster Mitigation for Engineers and Planners, 1st Edition, Elsevier, DOI: 10.1016/B978-0-12-801060-0.00008-3

Takagi H., Thao N. D., Esteban M., Mikami T., Cong L.V., Ca V. T. (2015c) Coastal Disasters in Vietnam, IN: Esteban M., Takagi H., Shibayama T. (eds) Handbook of Coastal Disaster Mitigation for Engineers and Planners, pp.235-255, DOI: 10.1016/B978-0-12-801060-0.00012-5

Takagi H., Esteban M. (2015) Statistics of Tropical Cyclone Landfalls in the Philippines -Unusual Characteristics of 2013 Typhoon Haiyan, Natural Hazards, 12 p., DOI:10.1007/s11069-015-1965-6

Tajima Y., Yasuda T., Pacheco B., Cruz E., Kawasaki K., Nobuoka H., Miyamato M. Asano Y., Arikawa T., Origas N. M., Aquino R., Mata W., Valdez J., Briones F. (2014) Initial report of JSCE-PICE joint survey on the storm surge disaster caused by Typhoon Haiyan, Coastal Eng. J., Vol.56, No.1, DOI: $10.1142 / \mathrm{S} 0578563414500065$ 
554 Tasnim K. M., Shibayama T., Esteban M., Takagi H., Ohira K., Nakamura R. (2015) 555 Field observation and numerical simulation of past and future storm surges in the 556 Bay of Bengal: case study of cyclone Nargis, Natural Hazards, Volume 75, Issue 2, 557 pp 1619-1647, DOI: 10.1007/s11069-014-1387-xTIME (2013) The Typhoon’s Toll, 558 TIME $\quad$ Magazine, $\quad$ Vol.182, No.22. 559 http://content.time.com/time/magazine/0,9263,7601131125,00.html\#ixzz2lY0n8A4 $560 \quad$ C (Accessed on December 20, 2013)

561 Wright, K., Doody, B. J., Becker, J., McClure, J. (2010) Pedestrian and motorist flood 562 safety study: a review of behaviours in and around floodwater and strategies to $563 \quad$ enhance appropriate behaviour, GNS Science Report 2010/51, 91 p. 